\title{
The Response of Outer Containment of Nuclear Reactor in Aircraft Crash
}

\section{Reza Saberi', Majid Alinejad², Farid Ghorbani', Kamran Sepanloo' $^{1}$}

${ }^{1}$ Nuclear Science and Technology Research Institute, P.O.Box
113658486, Tehran, Iran
${ }^{2}$ Engineering Research Institute of Natural Hazard
Shakhespajouh, Isfahan, Iran,
${ }^{3}$ Department of Civil Engineering, Khaje Nasireddin Toosi
University of Technology, Tehran, Iran
Study Area: Bandar Abbas, Iran
Coordinates: $27^{\circ} 11^{\prime} \mathrm{N} ; 56{ }^{\circ} 16^{\prime} \mathrm{E}$

Key words: Non-linear analysis, ABAQUS, Collapse anchor

\begin{abstract}
The impact of aircraft crash on concrete outer containment of nuclear reactor has been aimed to know. After 9/11 terrorist attacks and aircraft crashes with Twin Towers in the United States, the issue of nuclear safety and sustainability against plane crashes get more concerned. Destruction or damages of a nuclear power plant can lead to large-scale release of radioactive material and consequently it can bring about human and environmental disasters. In this article, the behaviour and response of concrete outer containment of nuclear reactor during a crash or moment loading is analysed through modelling Boeing-707 and Boeing-747 aircraft and also Phantom-F4 military aircraft. Dynamic load the aircraft is stimulated by using Riera's time-force curve. During the crash impact load and explosion occur simultaneously, and then it is applied to critical location where dome caps are connected to cylindrical walls of reinforced concrete nuclear reactor. Assessment of this clash is done by stimulation of concrete outer containment of nuclear reactor ABAQUS software. The behaviour of two containment areas of the nuclear reactor, i.e. the cylindrical body and the junction of the cylindrical dome cap, are evaluated in this paper. The results show a similar behaviour of reinforced concrete reactor chamber when the aircraft crashes with the dome cap and cylindrical wall than other parts of the reactor chamber.
\end{abstract}

forces while explosion cause. Furthermore, the effects of such crash could also cause the death/injury of the nuclear scientists and destruction of vegetation and organisms within several hundred kilometres. Hence, the response of the outer containment of nuclear reactor depends on the aircraft's crash and its explosion. From a safety point of view, the aim is to recognise eventuality and strategies for immunisations of reactors against terrorist attacks and dealing with its consequences (Frano \& Forasassi, 2011).

Concrete's response against crash's loading is very different from the static load. In the top of it tensile resistance pressure, and initial stiffness increases due to the effects caused by the deformation and strains (Abbas et al., 1996). Generally, we can say that accurately predicting the crash with concrete structures which are armed with appropriate numerical techniques, structural equation modelling and material properties would come in handy in structural equation (Iqbal et al., 2012). Today, the reactor would be the first defence system against the

*Corresponding Author: saberinuc@gmail.com 
numerical methods along with analytical and experimental approaches help a lot in solving problems and understanding the various physical phenomenon. Those consequences which usually happens during highspeed dynamic processes in experimental tests is usually difficult to observe and record. While in a numerical analysis, the whole process could be simulated (Arros \& Doumbalski, 2007).

Due to uncertainties in a modelling aircraft crash, the results of this article is hypothetic upto a far extent. In the present study, through the modeling nuclear reactor, the behaviour of two points out of the container of the reactor have been analysed and the details of the results are extracted from the software.Further, according to the dynamic behaviour of the concrete, when encountering problems and resistance at strain rates gets higher than the yield point, we would use yield strength which is dependent on the pressure. In this study, displacement of the point of crash and stress in the consumed steel has been considered a criterion for sustainability. The main objective of our research is to investigate the effects of aircraft crashes in a nuclear reactor's holding chamber based on the latest and most comprehensive existing regulations so that structural performance could be evaluated in two parts. The two parts of the reactor, i.e. reactor cylindrical body and the junction body of the reactor dome cap, is being investigated here.

Aircraft Crash with Outer Containment of Nuclear Reactor: the Nuclear reactor is a device for carrying out regulated and monitored nuclear reactions. This device is built in laboratory-sizes to produce isotopes of radioactive materials as well as radiation-drugs for medical purposes and also in industrial-sizes to generate electricity (Sadique etal., 2013).

Worldwide, while producing energy using fossil fuels is getting more expensive, nuclear electricity producing in the nuclear power plants using nuclear fission reaction is an excellent source for electricity generation. Generating electricity with nuclear methods aside from being inexhaustible, does not even produce greenhouse gases. The only problem it has is the nuclear waste it produces. If they are properly protected, they will have no harmful impact on the environment (Lee et al., 2013; Jeon et al., 2012). Apart from the laboratories, equipment the central part of the nuclear reactor, possess a special structure for the accessories that not only because it accommodate equipment but is very exceptional due to its strength, construction materials properties, being isolated from the environment it is also resistant against terrorist attacks, earthquakes, corrosion and access to special services (Drittler \& Gruner, 1976a). In a nuclear power plant, concrete chamber of a reactor holds the reactor core in itself. This is the only reason to have it the most elasticity against temperature, pressure and radiation. The core of the reactor is located at the bottom of the pressure vessel and between been the fortified concrete structure. It is also one of the main components of nuclear reactors that can not be replaced (Drittler \& Gruner, 1976b).

In 1986, the National Regulatory Commission (a.k.a. AEC) in the US was asked to evaluate the impact of aircraft crash with a power plant at Three Mile Island in the south of the country. In this evaluation, fire effects were considered as one of the possible initial damages (Petrangeli, 2010). For the first time in history, Riera (1968) conducted an assessment of the aircraft crash on structures and concrete walls (Fig.-1). In his research, Riera (1968) assumed that if a projectile hits the target part of the projectile that is closer to the target would get shattered and the remaining part would undergo an elastic deformation.

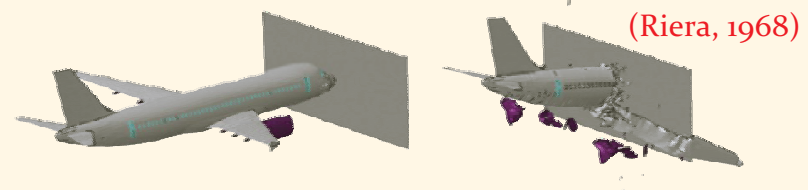

Figure 1: Model of an Aircraft Crash with a Concrete Wall

During the mid-197os, the impact of aircraft crash with the standard load for designing the nuclear reactor was considered in Germany. The design of nuclear reactors began by taking into account the extra load caused by the aircraft crash with the outer shell of a nuclear reactor in addition to dynamic loads of wind and earthquake. Also, after September 11th incident, Henkel \& Klein (2007) played an important role in the design of new nuclear reactors (Riera, 1968). Including Germany, today in various countries, there are plans that are being implemented to secure nuclear reactors against aircraft attacks (Abbas et al., 1995). One of the earliest research on aircraft crash with reactor compartment was conducted in 1996 by (Abbas et al., 1995) used numerical models and equations to obtain structural response (Bignon \& Doumbalski, 1980). Lee et al. (2013) examined the impact of a Boeing 747 crash on prestressed structure of a reactor. They evaluated the impact of aircraft crash with cylindrical body of the reactor and obtained tension in the consumed steel and displacement of hit point. They came to the conclusion that the angle of aircraft crash with the reactor's maintenance building's wall does not affect the response of the structure.

Due to the increasing risk of attack, Iran has also faced several attacks on nuclear reactors and hence it is important to pay special attention to this vital issue. In this article, the response of two areas from the concrete chamber of the nuclear reactor during aircraft crash is investigated.

Introduction of the Model: nonlinear analysis of reinforced concrete chamber of the reactor was performed using ABAQUS software where the analysis was based on 
Damage Plasticity. Stress, strain and displacement caused by the aircraft crash is investigated in two parts of the chamber. Reinforced concrete chamber of the reactor consists of a cylindrical structure on top of it which has a hemispherical (dome) shape. There is a steel plate on the inside to prevent the release of radioactive material that has been used. The height of the inner cylinder is $4 / 38$ meters and The total height of the structure (internal) is 4/56 meters. The thickness of the layer and structure is 37.1 meters that reach $76 /$ o meters toward the top of the cap. Foundation thickness is also 1/3 meters.
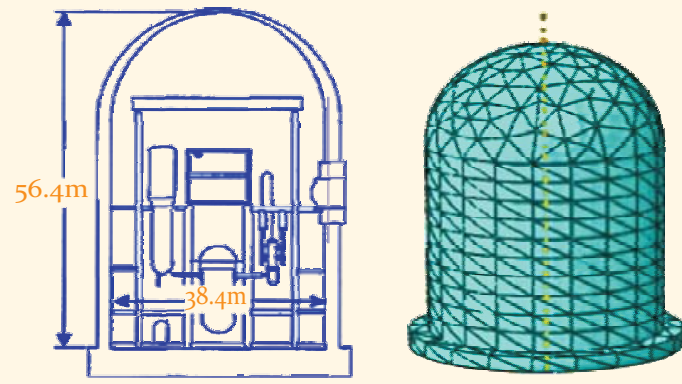

Figure-2: Image of the Image of reinforced concrete chamber and mesh model in the software

The pushing pressures for reinforced concrete chamber and modulus of elasticity are respectively considered 6/27 Mpa and 8/24 GPa, and Poisson's ratio is assumed to be $18 / 0$. Steel cover sheet is based on $\mathrm{A}_{516} 6$ grade 6o. Net weight of the outer shell of a nuclear reactor is $20550000 \mathrm{~kg}$. Table 1 shows the consumption of concrete and steel for modelling reactor chamber.

Table 1: Specifications of the Modeled Reactor Chamber

\begin{tabular}{|c|c|c|}
\hline Size & Specifications & Material \\
\hline $\begin{array}{l}\text { 1. (Mpa) 6/27 } \\
005 / 0\end{array}$ & $\begin{array}{l}\text { coeff icient of elastic modulus } \\
\text { pushing resistance } \\
\text { shear strain. }\end{array}$ & Concrete \\
\hline $\begin{array}{l}\text { 2. (Mpa) } \\
\text { (Mpa) } 420 \\
\text { May-oo }\end{array}$ & $\begin{array}{l}\text { Elastic modulus } \\
\text { Yield stress } \\
\text { The tensile strain }\end{array}$ & $\begin{array}{l}\text { Rebar } \\
\text { (Reinfor- } \\
\text { cement) }\end{array}$ \\
\hline
\end{tabular}

The soil characteristics of reactor model have cubic $200 \mathrm{x} 200$ $\mathrm{x} 50$ dimension and also it has type 2 earth. To put the structure in the soil, we have used nonlinear circuit elements (GAP) between $\mathrm{RC}$ and soil. These elements consist of springs with nonlinear behaviour so that it would not tolerate any force under tensile forces and in the compression zone shows a nonlinear behaviour. In modelling with software, the relative motion between successive horizontal reinforced concrete move and the soil beneath it was neglected. In other words, it is assumed that the RC slip was prevented on the soil. When studying the behaviour of concrete reactor compartment, impact loading of Boeing-707 and Boeing-747 aircraft along with Phantom-F4 military aircraft are used. Table-2 shows the characteristics of these aircraft.

Models studied in this research were the high-prof ile reactor containment structures that were analysed for the first time with considering aircraft crash with the cylindrical part and second time with taking into account the connection point of the cylindrical part with cap dome. Extra loading caused by Boeing707, Boeing-747 and military aircraft Phantom-F4 crash create stress and strain in the reactor chamber which were analysed in two parts of the reactor chamber. The reactor was designed using ASCE 43-05 Regulations.

Table 2: Aircraft Characteristics

\begin{tabular}{lll}
\hline Speed $(\mathrm{m} / \mathrm{s})$ & Weight $(\mathrm{kg})$ & Type \\
\hline 240 & 150000 & Boeing 707 \\
250 & 350000 & Boeing 747 \\
210 & 28000 & Phantom-F4 \\
\hline
\end{tabular}

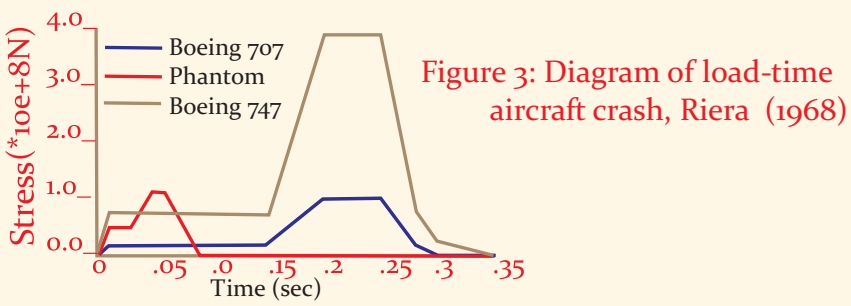

There are several models in ABAQUS software for concrete. In this article, we have used the most comprehensive model named Concrete Damage. As it can be seen in Fig.-3, Riera;s load-time diagram to analyse Boeing-707, Boeing-747 and Phantom-F4 military aircrafts. The horizontal line represents time and the vertical line expresses the loading crash of the aircraft.

Comparison of the Displacement and Stress Results in the Reactor Chamber: to investigate the nonlinear behaviour of shear walls, it is essential to choose a suitable shell element applicable to non-linear behaviour. We had used complete shell elements to meet the models' requirements. When we used this element in our analysis, there was a possibility to create models of such behaviours as plasticity, Haypralastysyth, viscoelasticity, viscoelasticity, elasticity, large deformation, large strain, hardening tensions. There was the also possibility of removing the defective elements too. It was even possible to define new layers to it. This four-node element has six degrees of freedom. The design force out of aircraft crash is obtained by calculating the kinetic energy caused by aircraft crash with the body of a nuclear reactor. Some of the kinetic energy is dissipated due to the fragmentation and distortion of the aircraft. Aircraft is a very soft projectile. Therefore, the crash energy solely depends on the distribution of mass and velocity of the aircraft. The total energy of the crash leads to the destruction of the aircraft near the hit point. The next important issue concerning large deformations is related to finite element theory. With discretization of the continuum environment for the object, each of the elements is joined to a shared point called nodes. During the application of large deformations, the elements' behaviours are very important. For describing the behaviour of the elements, in this case, there are several methods which can be described as Eulerian/spatial or Lagrangian/material. In 
Lagrangian description which has been discussed in solid mechanics more, elements nodes and Gauss points are adapted on the material points of the object and move it. In large deformations, there was a possibility of uncontrolled displacement of the nodes that can cause distortion of the elements and lead to some serious problems when results were being analysed. In the Eulerian description of the boundaries of elements and nodes were placed in the space and the materials could pass through the boundaries. The same description was used in fluid mechanics too. The weakness of this method was that it needs reforms and improvements in the border along the analysis. In the discretized environment with Euler element in it, materials pass through the outermost boundaries of the model in the space and change the boundary conditions. Therefore, the above description does not apply in solid mechanics.

At this stage, we had obtained the displacement of the crash point with the body of the nuclear reactor. Figute4/A demonstrates the maximum displacement coverage when Phantom $\mathrm{F}_{4}$ hits the cylindrical wall of the cap dome. Figure-4/B used the finite element software and shows the aircraft crash with the junction of dome cap to the cylindrical body in the reactor chamber.
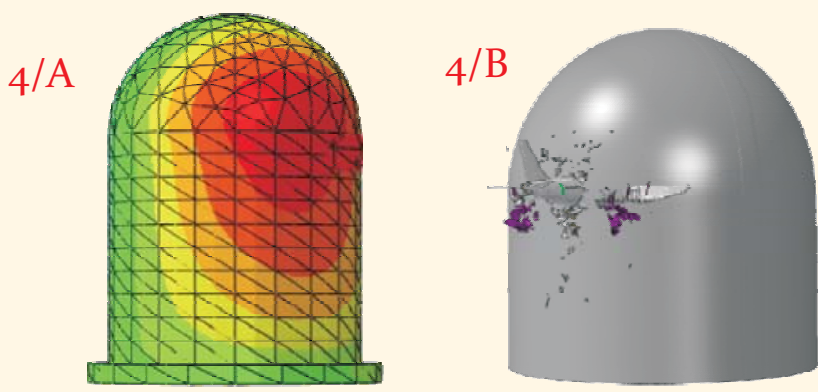

Figure 4/A: Strain of reinforced concrete of the chamber during an aircraft crash with the junction of the cylindrical wall of the capdome.

Figure 4/B: Modeling aircraft crash with the junction of dome cap to cylindrical body in the software

After modelling the concrete chamber of the reactor in ABAQUS software and performing analysis on two parts of it, the amount of displacement on two points of the chamber would be obtained. Figures 5 to 7 represent displacement changes of the aircraft crash point on the body of the reactor. These figures show us a comparison of the displacement between two hit points from the reactor's chamber when either one of oeing-707, Boeing747 and military aircraft Phantom-F4 crashes into it. The Horizontal axis of the diagram represents the time (in seconds) and the vertical axis represents the displacement (in meters) of where aircraft crashes.

As it can be seen in Fig.-8, displacement of aircraft crash point with the reactor is very prominent in the case of
Phantom F4. According to figures 5 to 7 , displacement of two points in the concrete reactor chamber is almost the same when there is extra loading involved. The average percentage of displacement difference between the two points of the body of the reactor is about $4 \%$. This indicates the similar behaviour of the chamber when an aircraft crashes in two points of it.

One of the basic parameters of the structural stability of the reactor chamber is tension in consumed steels. Steel tension is caused by the aircraft's crash with two parts, i.e. cylindrical body and the junction of the cylindrical body to dome cap. The amount of the tension in the steel reinforced concrete is obtained within the fraction of a second. In other words, in 25/o seconds after the crash with the reactor happens, some degree of stress is noticable in fig.- 8 to 10 .

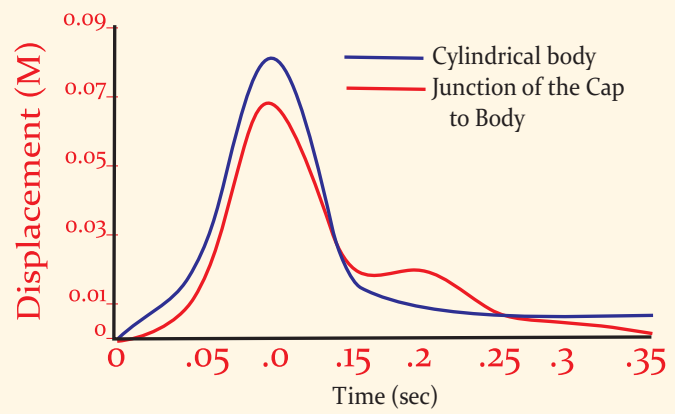

Figure 5: Comparison between two target displacement points in reactor chamber during Boeing 707 crash

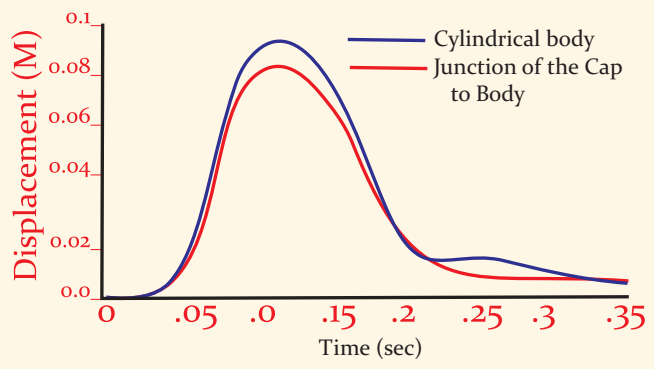

Figure 6: Comparison between two target displacement points in reactor chamber during Phantom $\mathrm{F}_{4}$ crash

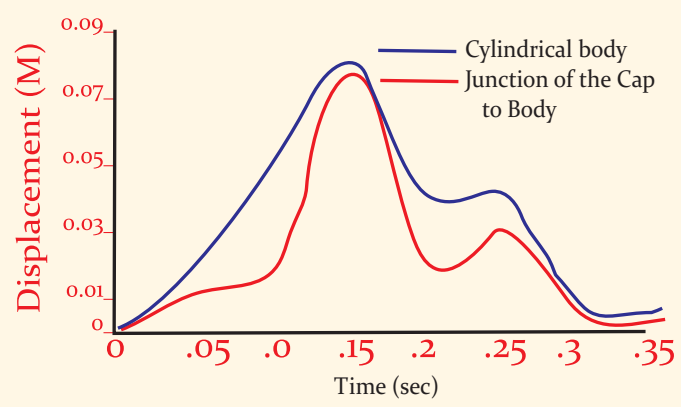

Figure 7: Comparison between two target displaceme points in reactor chamber during Boeing 747 crash 
TECHNOSCIENCE ARTICLE

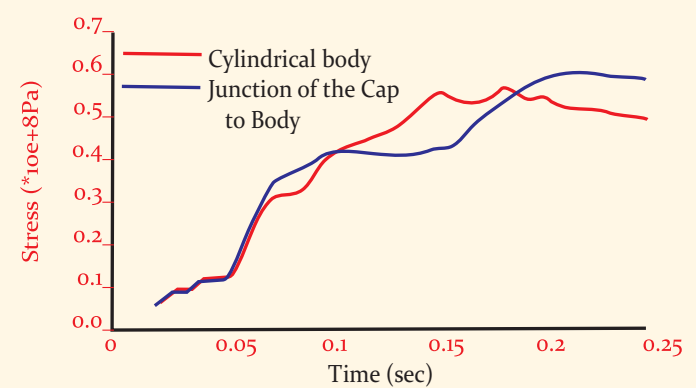

Figure 8: Comparison of the stress of two points in the reactor chamber during Boeing 707 crash

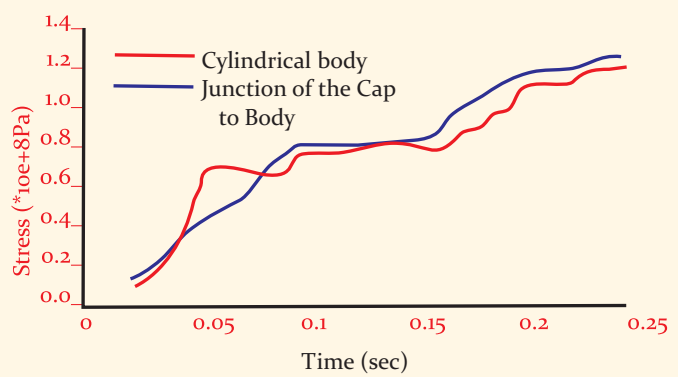

Figure 9: Comparison of the stress of two points in the reactor chamber during Phantom F4 crash

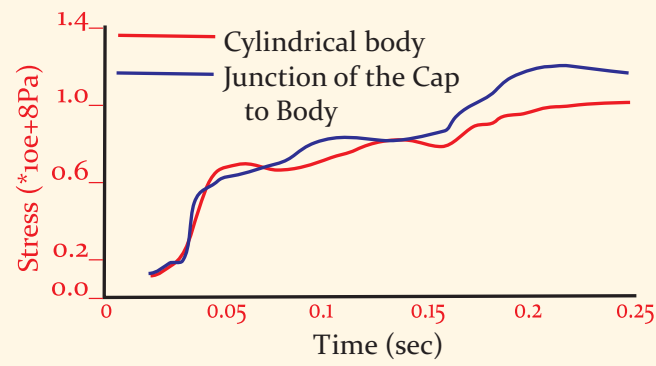

Figure 10: Comparison of the stress of two points in the reactor chamber during Boeing 747 crash

According to these figures, the tension in the steel reactor chamber is higher when Phantom $\mathrm{F}_{4}$ crashes on it. Also, the average percentage of the difference between two points of tension in the body of the reactor is about $12 \%$. In other words, the extraordinary stress caused by the crash at the junction of the cap to the reactor is more than cylindrical body of the reactor. The intensity and speed of the aircraft crash with the reinforced body of concrete nuclear reactor change the behaviour and characteristics of materials. In other words, in addition to the necessity of taking into account, the non-linear behaviour of materials, large deformation and geometric non-linear behaviour phenomenon could also be a major factor in the model. This leads to changes in concepts and basic assumptions that govern the strength of materials. Also, the criteria used in the analysis of normal strain has become discredited and requires a more comprehensive definition of strain and deformation. This is due to displacement and rigidity of materials' points of strain. In fact what happens as a displacement or rotation of body's
Ambient Science, 2017: Vol. 04(1); 45-50 DOI:10.21276/ambi.2017.04.1.ta04

cords without an increase or decrease in the length of the string, is rigid movements and in these type of analysis, due to small displacements, their effects are also negligible. According to this, large deformation phenomenon can be associated with large strains, or due to rigid movements despite large deformations, there will be small strains. The parameters that cause depreciation of forces generated through aircraft crash with the outer membrane of the nuclear reactor are the compressive strength of concrete, shear-friction resistance, and tensile strength. All three of these factors play an important role in creating tension in steel bars and deformation of the concrete body of the reactor.

\section{Conclusion:}

1. Boeing-707 and Boeing-747 aircraft along with Phantom-F4 military aircraft crash to the structure of nuclear reactors were stimulated. According to the results, Phantom- $\mathrm{F}_{4}$ has far greater potentials in destroying the reactor structure than Boeing-707 and Boeing-747.

2. The amount of tension in steel reinforced bars and displacement of target points in a nuclear reactor chamber is high when Phantom $\mathrm{F}_{4}$ crashes with it.

3. The target point in this study is the junction of the dome cap to the cylindrical body. In the case of aircraft crash with an external maintenance of nuclear reactor, tension in steel bars is greater and more noticeable at the junction of a cylindrical body with dome cap.

4. Displacement of aircraft's hit point with the reactor in both the cylindrical body of the reactor and the junction of the cylindrical body with dome cap is almost identical.

\section{Acknowledgements:}

We aknowledge all the persons involved in this study reight from the concerned in charge for providing permission to the person help in conducting the study.

\section{References:}

Abbas, H., Paul, D.K., Godbole, P.N., \& Nayak, G.C. (1995): Reaction-time response of aircraft crash. Comp. Struc., 55(5): 809-817.

Abbas, H., Paul, D.K., Godbole, P.N., \& Nayak, G.C. (1996): Aircraft crash upon outer containment of nuclear power plant. Nuc. Eng. Des., 160(1\&2):13-50.

Arros, J. \& Doumbalski, N. (2007): Analysis of aircraft impact to concrete structures. Nuc. Eng. Des., 237(12):1241-1249.

Bignon, P.G. \& Riera, J.D. (1980): Verification of methods of analysis for soft missile impact problems. Nuc. Eng. Des., 6o(3):311-326.

Drittler, K. \& Gruner, P. (1976a): The force resulting from impact of fast-flying military aircraft upon a rigid wall. Nuc. Eng. Des., 37(2):245-248.

Drittler, K., \& Gruner, P. (1976b): Calculation of the total force acting upon a rigid wall by projectiles. Nuc. Eng. Des., 37(2): 231-244. 
Frano, R. Lo, \& Forasassi, G. (2011): Preliminary evaluation of aircraft impact on a near term nuclear power plant. Nuc. Eng. Des., 241(12):5245-5250.

Henkel F. \& Klein D. (2007). Variants of Analysis of the Load Case Airplane Crash, Transactions of the 19th SMiRT, paper Jo3-2, Toronto.

Iqbal, M.A., Rai, S., Sadique, M.R. \& Bhargava, P (2012): Numerical simulation of aircraft crash on nuclear containment structure. Nuc. Eng. Des., 243:321-335.

Jeon, S-J., Jin, B-M. \& Kim, Y-J. (2012): Assessment of the fire resistance of a nuclear power plant subjected to a large commercial aircraft crash. Nuc. Eng. Des., 247:11-22.

Kar, K. (1979). "Impactive effects of tornado missiles and aircraft. J. Struc. Div., ASCE, 105( 11):2243-2260.
Lee, K., Han, S.E. \& Hong, J.W. (2013): Analysis of impact of large commercial aircraft on a pre-stressed containment building. Nuc. Eng. Des., 265:431-449.

Petrangeli, G. (2010): Large airplane crash on a nuclear plant: Design study against excessive shaking of components. Nuc. Eng. Des., 240(12):4037-4042.

Riera, J.D. (1968): On the stress analysis of structures subjected to aircraft impact forces. Nuc. Eng. Des., 8(4):415-426.

Sadique, M.R., Iqbal, M.A. \& Bhargava. P. (2013): Nuclear containment structure subjected to commercial and fighter aircraft crash. Nuc. Eng. Des., 260:30-46.

Wolf, J.P., Bucher, K.M. \& Skrikerud, P.E. (1978): Response of equipment to aircraft impact. Nucl. Eng. Des., 47(1):169-193. 